\title{
Staphylococcus ursi sp. nov., a new member of the 'Staphylococcus intermedius group' isolated from healthy black bears
}

\author{
Vincent Perreten', Stephen A. Kania ${ }^{2, *}$ and David Bemis²
}

\begin{abstract}
Six Staphylococcus strains were isolated from healthy black bears (Ursus americanus) in the Great Smoky Mountains National Park, Tennessee, USA. Phylogenetic analysis based on complete genome, $16 \mathrm{~S}$ rRNA, dnaJ, hsp60, rpoB and sodA genes, and MALDI-TOF-MS main spectral profiles revealed that the strains belonged to one species and showed the closest relatedness to members of the 'Staphylococcus intermedius group' (SIG), which include Staphylococcus intermedius, Staphylococcus pseudintermedius, Staphylococcus delphini and Staphyloccoccus cornubiensis. The strains were positive in SIG-specific and negative in individual species-specific PCR assays for the nuc gene. The strains can be differentiated from the other SIG species by the absence of sucrose fermentation, from S. intermedius DSM 20373 ${ }^{\top}$, S. pseudintermedius CCUG $49543^{\top}$ and S. cornubiensis DSM $105366^{\top}$ by the absence of methyl $\beta$-D-glucopyranoside fermentation and from S. delphini DSM $20771^{\top}$ by fermentation of trehalose. DNA relatedness of the type strain MI 10-1553 ${ }^{\top}$ with the type strains of S. delphini, S. pseudintermedius, S. intermedius and S. cornubiensis was $\leq 48.2 \%$ by digital DNA-DNA hybridization and $\leq 92.3 \%$ by average nucleotide identity calculations. ${ }^{\text {Iso- }}{ }_{\text {C15:0 }}$ anteiso- $C_{15: 0}$ and anteiso- $C_{17: 0}$ were the most common fatty acids. Polar lipids consisted of phosphadidylglycerols, phospholipids, glycolipid, diphosphatidylglycerol and aminophospholipid. Cell-wall peptidoglycan was of type A3 $\alpha$ L-Lys-Gly 3 (Ser; similar to A11.2 and A11.3). The respiratory quinone belonged to menaquinone 7 (MK-7). The G+C content of MI 10-1553 was 39.3 mol\%. The isolated strains represent a novel species of the genus Staphylococcus, for which we propose the name Staphylococcus ursi sp. nov. The type strain is MI 10-1553' (=ATCC TSD-55'=CCOS $1900^{\top}$ ).
\end{abstract}

\section{INTRODUCTION}

Over a number of years, bacteria that share colony morphotypes and overlapping phenotypic characteristics with Staphylococcus aureus were taxonomically segregated and assigned to new species, e.g. Staphylococcus intermedius [1], Staphylococcus delphini [2], Staphylococcus pseudintermedius [3], and Staphylococcus cornubiensis [4]. The above species are commonly referred to as the 'Staphylococcus intermedius group' (SIG). Phenotypic traits and $16 \mathrm{~S}$ rRNA gene sequencing do not readily differentiate between these closely related species [5]. SIG members are usually associated with various animal hosts; however, their presence in human infections may be underestimated due to the potential for misidentification as S. aureus [6-8]. Such misidentification can negatively affect interpretation of susceptibility test results and lead to inappropriate antimicrobial therapy $[8,9]$. As with $S$. aureus in people, $S$. pseudintermedius has been well characterized as an opportunistic pathogen in dogs and the frequency of infections caused by methicillin- and multidrug-resistant strains has been increasing in recent years [10]. Overall, little

Author affiliations: 'Institute of Veterinary Bacteriology, University of Bern, $\mathrm{CH}-3001$ Bern, Switzerland; ${ }^{2}$ Department of Biomedical and Diagnostic Sciences, University of Tennessee College of Veterinary Medicine, Knoxville, Tennessee, USA.

*Correspondence: Stephen A. Kania, skania@utk.edu

Keywords: Staphylococcus ursi; Staphylococcus intermedius group; black bear; Gram-positive; cocci; animals; Staphylococcaceae.

Abbreviations: ANI, average nucleotide identity; BHI, brain heart infusion; CAMP, Christie-Atkins-Munch-Petersen; dDDH, digital DNA-DNA

hybridization; GBDP, genome BLAST distance phylogeny; PFGE, pulsed-field gel electrophoresis; SIG, Staphylococcus intermedius group; TSA-SB,

trypticase soy agar containing $5 \%$ sheep blood.

The GenBank/EMBL/DDBJ accession numbers for the $16 \mathrm{~S}$ rRNA, hsp60, nuc, sodA, tagAHGBD, dnaJ and rpoB gene sequences of strain MI 10-1553 are KY019172, KY056141, KY056142, KY056143, KY056144, KY496628 and KY496627 respectively. The complete genome sequence of strain MI 10-1553 ${ }^{\top}$ has been deposited into GenBank under accession numbers CP048279. The associated BioProject and BioSample accession numbers are PRJNA602989 and SAMN13915443, respectively. The raw reads were deposited into the SRA database with accession numbers SRR10973935 (Illumina) and SRR10973936 (ONT).

Four supplementary figures are available with the online version of this article. $004324 \odot 2020$ The Authors 
is known about the host range and population distribution of species within the SIG. It has been suggested, for example, that strains identified as $S$. pseudintermedius by traditional means from hosts other than dogs should be more thoroughly investigated by phylogenetic analysis before reporting [5]. The objectives of this work were to seek SIG isolates from healthy wild bears and to confirm their species identity by polyphasic taxonomic characterization. Such strains will be useful for future comparisons to existing collections for the purpose of examining their diversity and potential to exchange virulence and resistance traits.

During a surveillance study for the presence of staphylococci, cutaneous samples for culture were obtained from 15 healthy black bears (Ursus americanus) that had been captured and tranquilized for relocation, or, in one case, hit by a car and euthanized, in the Great Smoky Mountains National Park, Tennessee, USA, during 2010. All animal handling and sample collections were performed by trained and certified National Park Service wildlife biologists. Culture swabs (Becton Dickinson) were used to collect samples from the nasal cavity and a minimum of two additional pre-defined sites (nasal, oral lip folds, inguinal skin or external ear) from each animal. Swabs in Amies medium (Becton Dickinson) were kept cool while in the field and transported for processing within 24-48 h. Swabs were inoculated onto colistin-nalidixic acid agar (Becton Dickinson) containing 5\% sheep blood. The plates were incubated at $35^{\circ} \mathrm{C}$ for $24-48 \mathrm{~h}$. A representative of all colony types resembling those of staphylococci and that were catalase-positive, Gram-stain-positive cocci were inoculated onto trypticase soy agar containing $5 \%$ sheep blood (TSA-SB; Becton Dickinson) and incubated at $35^{\circ} \mathrm{C}$ for $24 \mathrm{~h}$; subsequently, cell lysates were used as template DNA for universal bacterial 16S rRNA gene PCR followed by direct Sanger sequencing to obtain partial nucleotide sequences as described previously [11]. The 16S rRNA gene sequences of the strains were compared to sequences in the GenBank database using the BLASTn algorithm [12]. Strains resembling members of the SIG were further screened by partial thermonuclease gene (nuc) PCR using previously described group-specific [13] and species-specific [14] methods. Of the 108 strains screened, 61 were provisionally identified as belonging to the genus Staphylococcus and were distributed among 10 different species or groups of closely related species. Six strains, found in cultures from sample sites of five animals, had large ( $>5 \mathrm{~mm})$, smooth, off-white colony morphologies resembling those of SIG members, displayed $\alpha$ hemolysis on sheep blood agar and were catalase-positive, Gram-stain-positive cocci. The strain designations and their corresponding animal, gender and sample site from which they were isolated were as follows: MI 10-1549, bear 1, female, nasal; MI 10-1553, bear 2, female, oral lip fold; MI 10-1558, bear 3, female, oral lip fold; MI 10-1605, bear 4, male, inguinal skin; MI 10-1708, bear 5, female, oral lip fold; MI 10-1710, bear 5, female, external ear canal. The six strains contained 16S rRNA gene sequences that differed from those of known Staphylococcus species clustering with strains of the S. hyicus-intermedius species group [15] and appeared to be most closely related to members of the SIG (Fig. 1). The strains could not be assigned to any of the known species of the SIG using a species-specific nuc PCR assay which is the currently reliable and recommended method to rapidly identify members of this group [14]. The strains were, however, positive in the SIG-specific [13] PCR assay for the nuc gene. These six strains were not clonally related as demonstrated by pulsed-field gel electrophoresis (PFGE; Fig. S1, available in the online version of this article) and were selected for further identification and characterization. PFGE was carried out using DNA digested with Cfr9I as described previously [16]. PFGE was run in $1 \%$ agarose gel in $0.5 \times \mathrm{TBE}$ on a Bio-Rad CHEF-DR III system for $18 \mathrm{~h}$ with pulse from 0.5 to $15 \mathrm{~s}$ and for $5 \mathrm{~h}$ with pulse from 20 to $25 \mathrm{~s}$ and at $14^{\circ} \mathrm{C}$ and $5.6 \mathrm{~V} \mathrm{~cm}^{-1}$.

Whole-genome sequencing was performed for strain MI 10-1553 $3^{\mathrm{T}}$ using the MinION R.9.4.1 flow cell (Oxford Nanopore Technology), Novaseq6000 (Illumina), Ion Torrent sequencing technology (Thermo Fisher Scientific) and assembled with Unicycler (version 0.4.4). The resulting assembled sequence consisted of a $2896994 \mathrm{bp}$ chromosome which was annotated using the NCBI Prokaryotic Genome Annotation Pipeline (GenBank acc. no. CP048279). The genome sequence was used to perform digital DNA-DNA hybridization (dDDH) and average nucleotide identity (ANI) calculations, whole genome comparative analysis, and to obtain DNA sequences for the $16 \mathrm{~S}$ rRNA, nuc, dnaJ, hsp60, rpoB and sodA genes as well as the operon coding for teichoic acid biosynthesis. The 16S rRNA gene sequence of strain MI 10-1553 ${ }^{\mathrm{T}}$ (GenBank acc. no. KY019172) clustered into the phylogenetic branch of the SIG (Fig. 1) and shared $\leq 99.7 \%$ identity to the sequence of the other SIG type strains using the lalign program [17] (Table 1). The 16S rRNA of the novel species shared 99.2\% identity with Staphylococcus schleiferi subsp. coagulans ATCC $49545^{\mathrm{T}}$, which is the next closest Staphylococcus species to those of the SIG group, was provisionally also isolated from some of the bear samples in this study and that is commonly found in body sites occupied by $S$. pseudintermedius in dogs [10]. Specific regions of the dnaJ [18], hsp60 [19], rpoB [20] and $\operatorname{sodA}[21]$ genes, which have been frequently used for molecular identification of staphylococci, were also amplified by PCR from the $S$. ursi strains using primers and conditions presented in Table S1 and sequenced. Alignment of these regions with those of the S. hyicus-intermedius group showed that the six strains were closely related but differed from those of SIG members (Table 1, Fig. S2). The DNA region of sodA (416bp; GenBank acc. no. KY056143) was identical in each S. ursi strain and shared $\leq 97.6 \%$ DNA identity to the sequence of the SIG type strains. The hsp60 region (552 bp; GenBank acc. no. KY056141) was identical in each $S$. ursi strain and showed $\leq 92.9 \%$ DNA identity to that of the SIG type strains. The DNA of the rpoB region (476bp; GenBank acc. no. KY496627) shared $99.8 \%$ between all S. ursi strains and $\leq 96.6 \%$ DNA identity to that the SIG type strains. The DNA of the dnaJ region (883 bp) (GenBank acc. no. KY496628) shared $99.8 \%$ between all $S$. ursi strains and $\leq 96.1 \%$ DNA identity to that of the SIG type strains. The complete nuc gene of S. ursi MI 10-1553 ${ }^{\mathrm{T}}$ (GenBank acc. no. KY056142) showed 


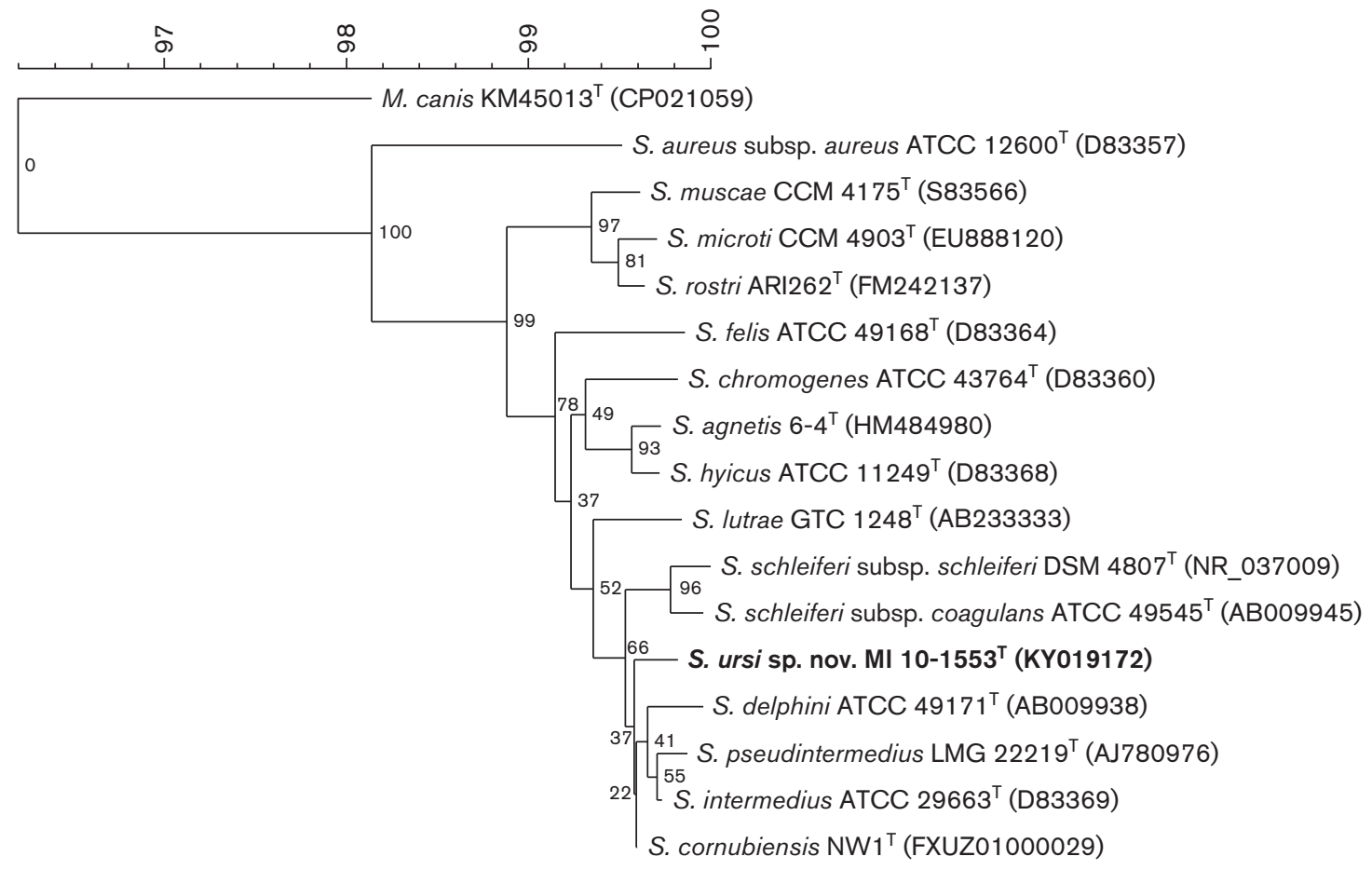

Fig. 1. Phylogenetic tree reconstructed from 16S rRNA gene sequences of Staphylococcus ursi sp. nov. and the other Staphylococcus species of the Staphylococcus hyicus-intermedius species group, as well as S. aureus. The tree was generated by neighbour-joining analysis [Multiple alignment (OG 100\%; UG 0\%), discard unknown bases, use active zones only, without fast algorithm] and Jukes-Cantor correction using BioNumerics 7.5 (Applied Maths). Bootstrap values are shown at each node as a percentage of 1500 replicates. The $16 \mathrm{~S}$ rRNA gene of Macrococcus canis KM45013' was used as outgroup to root the tree. The GenBank/EMBL/DDBJ accession numbers for sequences derived from each type strain are provided in the parentheses.

$\leq 93.7 \%$ identity to that of the other SIG type strains (Table 1 ). Since PCR assay targeting the nuc region is the currently recommended method to rapidly identify members of the SIG [14], specific primers nuc-S.ursi-F (5'-GCAGACACCTCG AAATCAATGTG) and nuc-S.ursi-R (5'-GGTATCCCCATC
TATCACGCGT) were designed in this study to specifically amplify a $593 \mathrm{bp}$ fragment of the nuc region of the S. ursi sp. nov. strains to distinguish $S$. ursi sp. nov. from the four type strains of other members of the SIG. PCR were performed using Taq polymerase and an initial denaturation step at $94^{\circ} \mathrm{C}$

Table 1. Percentage of identities of $16 \mathrm{~S}$ rRNA, specific regions of dnaJ, hsp60, rpoB, sodA, digital DNA-DNA hybridization (dDDH), and average nucleotide

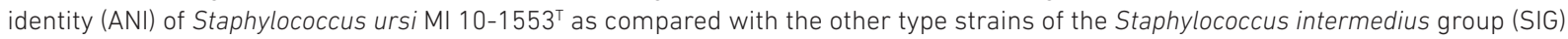

The ANI were calculated using OrthoANIu [24], and the dDDH was determined using the Genome-to-Genome Distance Calculator (GGDC) [23]. Identity between the genetic markers was determined using the lalign program [17]; ND, No cut off defined; Cl, confidential interval.

\begin{tabular}{|c|c|c|c|c|c|c|c|c|}
\hline $\begin{array}{l}\text { Type strains } \\
\text { (GenBank accession no. of the } \\
\text { genome) }\end{array}$ & \multicolumn{8}{|c|}{ Genetic features and cut off values [references] } \\
\hline $\begin{array}{l}\text { S. pseudintermedius LMG } 22219^{\mathrm{T}} \\
(\text { MLGE02000000) }\end{array}$ & 99.6 & 95.0 & 92.4 & 96.0 & 96.6 & 93.5 & $\begin{array}{c}46.5 \\
{[\text { CI } 43.9-49.1 \%]}\end{array}$ & 91.99 \\
\hline $\begin{array}{l}\text { S. intermedius NCTC } 11048^{\mathrm{T}} \\
\text { (UHDP00000000) }\end{array}$ & 99.7 & 92.4 & 91.7 & 95.0 & 91.6 & 89.2 & $\begin{array}{c}36.6 \\
{[\mathrm{CI} 34.1-39.1 \%]}\end{array}$ & 88.84 \\
\hline $\begin{array}{l}\text { S. cornubiensis } \mathrm{NW}^{\mathrm{T}} \\
(\mathrm{FXUZ0000000)}\end{array}$ & 99.7 & 91.3 & 92.9 & 92.9 & 95.9 & 86.4 & $\begin{array}{c}34.7 \\
{[\text { CI } 32.2-37.2 \%]}\end{array}$ & 87.95 \\
\hline S. delphini NCTC $12225^{\mathrm{T}}$ (LR134263) & 99.4 & 96.1 & 92.2 & 96.6 & 97.6 & 78.7 & $\begin{array}{c}48.20 \\
\text { [CI } 45.6-50.8 \%]\end{array}$ & 92.32 \\
\hline
\end{tabular}


for $3 \mathrm{~min}$, followed by 35 cycles of denaturation at $94^{\circ} \mathrm{C}$ for $30 \mathrm{~s}$, annealing at $54^{\circ} \mathrm{C}$ for $30 \mathrm{~s}$ and elongation at $72^{\circ} \mathrm{C}$ for $50 \mathrm{~s}$.

The genome sequences were uploaded to the Type (Strain) Genome Server (TYGS) hosted at the Leibniz Institute DSMZ, Germany (https://tygs.dsmz.de) for whole-genome comparative analysis and dDDH calculations [22]. All pairwise comparisons among the set of genomes were conducted using genome BLAST distance phylogeny (GBDP) and intergenomic distances inferred under the algorithm 'trimming' and distance formula $\mathrm{d} 5$ with a 100 distance replicates calculation [23]. The dDDH values and confidence intervals were calculated using the recommended settings and formula $\mathrm{d} 4$ of the Genome-to-Genome Distance Calculator (GGDC version 2.1) [23]. The ANI value of the genome of S. ursi MI $10-1553^{\mathrm{T}}$ as compared to the other SIG type strains has been calculated using orthoANIu [24].

A balanced minimum evolution tree of strain MI 10-1553 ${ }^{\mathrm{T}}$ and its next-related Staphylococcus species was reconstructed using the intergenomic distances obtained from the GBDP analysis and with branch support (100 pseudo-bootstrap replicates) via FASTME 2.1.4 and including subtree pruning and regrafting postprocessing [25]. The tree was visualized using iTOL (https://itol.embl.de/) [26] (Fig. 2). Phylogenetic relationships of the novel strains and other staphylococcal species were also determined for $16 \mathrm{~S}$ rRNA gene, sodA, hsp60, dnaJ and $r p o B$, and analysing sequences using BioNumerics 7.5 (Applied Maths). The trees were generated by the neighbour-joining method [multiple alignment (OG 100\%; UG 0\%), discard unknown bases, use active zones only] using the Jukes-Cantor correction. Bootstrap values were determined from 1500 replications. The phylogenetic trees showed that the novel strains, as represented by strain MI 10-1553, clustered within the S. hyicus-S. intermedius group [15] and are most closely related to the SIG (Figs 1, 2 and S2).

Strain MI 10-1553 ${ }^{\mathrm{T}}$ also differed from the type strains of species within the SIG by dDDH and ANI analyses. A threshold value of 70\% DNA-DNA relatedness and of $95-96 \%$ ANI for the definition of bacterial species was considered as recommended $[27,28]$. Strain MI 10-1553 ${ }^{\mathrm{T}}$ did not belong to known species within the SIG with $\mathrm{dDDH}$ values $\leq 48.20 \%$ and with ANI values $\leq 48.2 \%$ with the genome of $S$. delphini NCTC $12225^{\mathrm{T}}\left(=\mathrm{DSM} 20771^{\mathrm{T}}\right)$, S. pseudintermedius LMG $22219^{\mathrm{T}}$

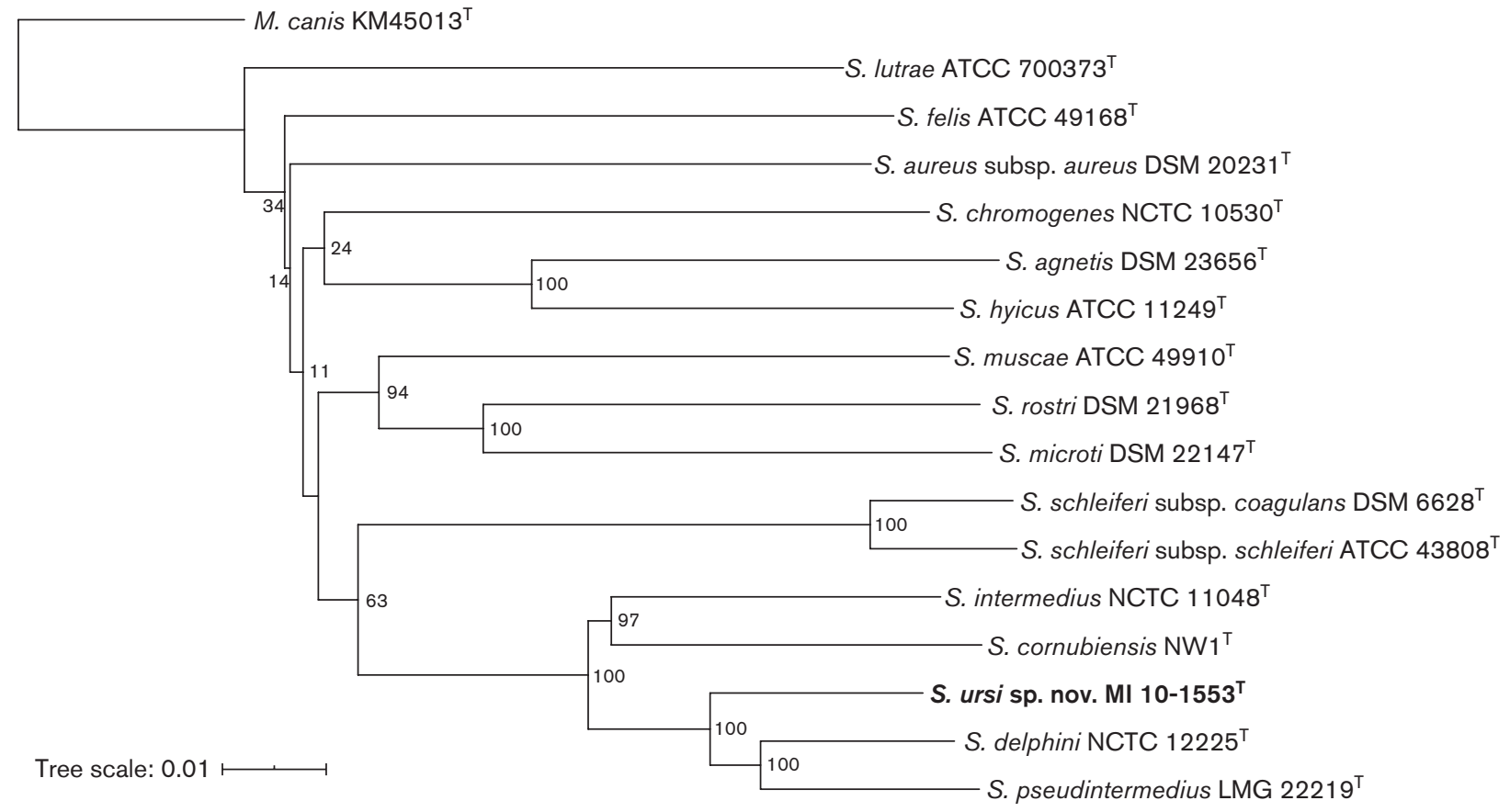

Fig. 2. Balanced minimum-evolution tree containing strain MI 10-1553 and the other type strains of the Staphylococcus hyicus-intermedius group, as well as S. aureus. The tree was generated using the Type (Strain) Genome Server (TYGS) (https://tygs.dsmz.de) including the following whole genome sequences: S. aureus subsp. aureus DSM 20231 ${ }^{\top}$ (NZ_CP011526.1), S. muscae ATCC 49910 (NZ_CP027848.1), S. microti DSM 22147 (JXWY01000001-JXWY01000186), S. rostri DSM 21968 (PPRF01000001-PPRF01000167), S. felis ATCC 49168 (NZ CP027770), S. chromogenes NCTC10530 (UHDB01000001-UHDB01000002), S. agnetis DSM 23656 (PPQF01000001-PPQF01000164)، S. hyicus ATCC 11249 NZ_CP008747), S. lutrae ATCC 700373 (NZ_CP020773.1), S. schleiferi subsp. coagulans DSM 6628 (PPQN01000001PPQN01000155), S. schleiferi subsp. schleiferi ATCC 43808 (POVK01000001-POVK01000088), S. delphini NCTC12225 ${ }^{\top}$ (NZ_LR134263), S. pseudintermedius LMG 22219 (MLGE02000001-MLGE02000036), S. intermedius NCTC 11048 (UHDP01000001-UHDP01000003), S. cornubiensis NW1 ${ }^{\top}$ (FXUZ01000001-FXUZ01000136), S. ursi sp. nov. MI 10-1553 (CP048279) and Macrococcus canis strain KM45013 ${ }^{\top}$ (NZ_CP021059). The tree was reconstructed using the intergenomic distances obtained from the GBDP analysis and with branch support (100 pseudo-bootstrap replicates) via FASTME 2.1.4 and including subtree pruning and regrafting postprocessing [25]. The genome of M. canis KM45013 ${ }^{\top}$ was used as outgroup to root the tree. The tree was visualized and rooted using iTOL (https://itol.embl.de/) [26] 
$\left(=\right.$ CCUG $\left.49543^{\mathrm{T}}\right)$, S. intermedius NCTC $11048^{\mathrm{T}}$ (=CCUG $\left.20373^{\mathrm{T}}\right)$, and $S$. cornubiensis $\mathrm{NW} 1^{\mathrm{T}}\left(=\mathrm{DSM} 105366^{\mathrm{T}}\right)$, which were the closest relatives by $16 \mathrm{~S}$ rRNA, dnaJ, hsp60, rpoB, sodA and whole genome sequence comparison (Table 1).

The DNA G+C content of strain MI $10-1553^{\mathrm{T}}$ was $39.3 \mathrm{~mol} \%$, as derived from the complete genome sequence. The $\mathrm{G}+\mathrm{C}$ contents are within the range of $33-40 \mathrm{~mol} \%$ reported for other Staphylococcus species [29]. Menaquinone profile, peptidoglycan structure, polar lipids and fatty acid composition were determined at the Leibniz Institute DSMZ-German Collection of Microorganisms and Cell Cultures, Germany. Fatty acid analysis was performed by gas chromatography (www.midi-inc.com). Fatty acid methyl esters were obtained from $40 \mathrm{mg}$ cells scraped from trypticase soy broth agar plates incubated at $28^{\circ} \mathrm{C}$ for $24 \mathrm{~h}$ by saponification, methylation and extraction using minor modifications of the method of Miller [30] and Kuykendall et al. [31]. The fatty acid methyl esters mixtures are separated using Sherlock Microbial Identification System (MIS; MIDI, Microbial ID) which consisted of an Agilent model $6890 \mathrm{~N}$ gas chromatograph fitted with a 5\% phenyl-methyl silicone capillary column $(0.2 \mathrm{~mm} \times 25 \mathrm{~m})$, a flame ionization detector, Agilent model 7683A automatic sampler and an HP-computer with the MIDI database (Hewlett-Packard). Peaks are automatically integrated and fatty acid names and percentages calculated by the MIS
Standard Software (Microbial ID). The gas chromatographic parameters are as follows: carrier gas, ultra-high-purity hydrogen; column head pressure $60 \mathrm{kPa}$; injection volume $2 \mu \mathrm{l}$; column split ratio, 100:1; septum purge $5 \mathrm{ml} \mathrm{min}^{-1}$; column temperature, $170-270^{\circ} \mathrm{C}$ at $5^{\circ} \mathrm{Cmin}^{-1}$; injection port temperature, $240^{\circ} \mathrm{C}$; and detector temperature, $300^{\circ} \mathrm{C}$. Fatty acids iso- $\mathrm{C}_{15: 0}$, anteiso- $\mathrm{C}_{15: 0}$ and anteiso- $\mathrm{C}_{17: 0}$ were the most abundant fatty acids in strain MI 10-1553 ${ }^{\mathrm{T}}$. With the exception of anteiso- $\mathrm{C}_{17: 0}$, these fatty acids were also the most common in the other species of the SIG (Table 2).

The peptidoglycan structure of strain MI $10-1553^{\mathrm{T}}$ was determined as previously described using cells grown in brain heart infusion (BHI) broth (BBL, Becton Dickinson) at $37^{\circ} \mathrm{C}$ for $18 \mathrm{~h}$ [32]. Total hydrolysates $\left(4 \mathrm{~N} \mathrm{HCl}, 16 \mathrm{~h}, 100^{\circ}\right.$ C) of the peptidoglycan in strain MI $10-1553^{\mathrm{T}}$ contained the amino acids Lys, Ala, Ser, Gly and Glu in molar ratios of $0.9,1.4,0.3,2.8$, and 1.0 , respectively. The identity of amino acids was confirmed by GC/MS (GC/MS 320 Singlequad, Varian). Partial hydrolysates of the peptidoglycan $(4 \mathrm{~N} \mathrm{HCl}$, $0.75 \mathrm{~h}$ at $100^{\circ} \mathrm{C}$ ), determined by $2 \mathrm{D}-\mathrm{TLC}$, revealed the presence of peptides L-Ala-D-Glu, Ala-Gly, L-Lys-Gly, D-Ala-LLys-Gly, oligo-Gly. The peptidoglycan type of MI 10-1553 ${ }^{\mathrm{T}}$ was A3 $\alpha$ L-Lys-Gly ${ }_{3}(\mathrm{Ser})$ and was similar to types A11.2 and A11.3 according to the system proposed by Schleifer and Kandler [33] for the characterization and representation of

Table 2. Fatty acid composition of strain MI 10-1553 and other species of the Staphylococcus intermedius group

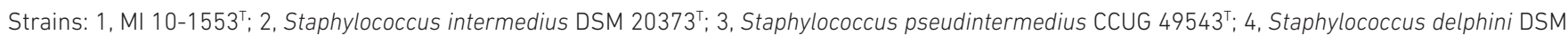
20771 ${ }^{\top}$; 5, Staphylococcus cornubiensis DSM 105366 ${ }^{\top}$. Values are percentages of total fatty acids. Major components (>10\%) are highlighted in bold. - , Not detected.

\begin{tabular}{|c|c|c|c|c|c|}
\hline Fatty acid & 1 & 2 & 3 & 4 & 5 \\
\hline iso- $\mathrm{C}_{14: 0}$ & 0.5 & 0.6 & - & 0.5 & - \\
\hline $\mathrm{C}_{14: 0}$ & 0.6 & 0.6 & - & 0.9 & - \\
\hline iso- $C_{15: 0}$ & 35.0 & 54.2 & 47.9 & 53.9 & 47.1 \\
\hline iso- $\mathrm{C}_{16: 0}$ & 1.1 & 1.3 & 1.3 & 0.9 & 1.8 \\
\hline$C_{16: 0}$ & 1.4 & 1.8 & 2.0 & 1.9 & 2.1 \\
\hline iso- $\mathrm{C}_{17: 0}$ & 9.4 & 7.9 & 11.7 & 5.9 & 13.9 \\
\hline anteiso- $C_{17: 0}$ & 13.6 & 3.0 & 5.6 & 3.8 & 5.9 \\
\hline $\mathrm{C}_{18: 0}$ & 1.6 & 2.5 & 2.5 & - & 2.6 \\
\hline iso- $C_{19: 0}$ & 1.1 & 0.7 & 1.1 & - & 2.9 \\
\hline anteiso- $\mathrm{C}_{19: 0}$ & 1.6 & - & 0.4 & - & - \\
\hline$C_{20: 2} \omega 6,9 c$ & - & 0.6 & 3.3 & - & - \\
\hline $\mathrm{C}_{20: 0}$ & 2.0 & 0.7 & 1.5 & - & 5.0 \\
\hline Unidentified & - & 0.4 & - & - & - \\
\hline
\end{tabular}


peptidoglycan types (www.peptidoglycan-types.info). The presence of serine and a reduced amount of glycine suggests that glycine is partially substituted by serine in the interpeptide bridge.

Respiratory lipoquinones and polar lipids were extracted from $100 \mathrm{mg}$ freeze-dried cell material from a $24 \mathrm{~h}$ culture in a trypticase soy yeast extract medium at $37^{\circ} \mathrm{C}$ using a the two-stage method described by Tindall $[34,35]$. Respiratory lipoquinones were extracted first followed by the polar lipids $[34,35]$. Respiratory lipoquinones were separated into their different classes (menaquinones and ubiquinones) by TLC on silica gel (Macherey-Nagel art. no. 805 023), using hexane/ tert-butyl methyl ether $(9 ; 1, \mathrm{v} / \mathrm{v})$ as solvent. UV-absorbing bands corresponding to menaquinones or ubiquinones were removed from the plate and analysed further by HPLC. This step was carried out on an LDC Analytical HPLC (Thermo Separation Products) fitted with a reversed-phase column (Machery-Nagel; $2 \times 125 \mathrm{~mm}, 3 \mu \mathrm{m}, \mathrm{RP} 18$ ) using methanol as the eluent. Respiratory lipoquinones were detected at $269 \mathrm{~nm}$. Strain MI 10-1553 ${ }^{\mathrm{T}}$ contained menaquinone 7 (MK 7).

Polar lipids were separated by two-dimensional silica gel TLC (Macherey-Nagel, Art. No. 818 135). The first direction was developed in chloroform-methanol-water $(65: 25: 4, \mathrm{v} / \mathrm{v} / \mathrm{v})$, and the second in chloroform-methanol-acetic acid-water $(80: 12: 15: 4, \mathrm{v} / \mathrm{v} / \mathrm{v} / \mathrm{v})$. Total lipid material was detected using molybdatophosphoric acid and specific functional groups detected using spray reagents specific for defined functional groups [36]. Polar lipids of strain MI 10-1553 ${ }^{\mathrm{T}}$ consisted of phosphadidylglycerol, diphosphatidylglycerol, two unknown aminophospholipids, two unknown phospholipids, two unknown glycolipids and two unknown lipids (Fig. S3).

The presence of teichoic acid in the novel species was determined by the detection within the genome of strain MI $10-1553^{\mathrm{T}}$ of the Tar/Tag operon (TagAHGBD) which is involved in the cell-wall teichoic acid biosynthesis [37].

No known antibiotic resistance and virulence genes were detected within the genome sequence of strain $10-1553^{\mathrm{T}}$ (GenBank acc. no. CP048279) using The Comprehensive Antibiotic Resistance Database (Card) (https://card. mcmaster.ca) and the Virulence Factor Database (VFDB) (www.mgc.ac.cn/VFs/main.htm).

Matrix-assisted laser desorption/ionization time-of-flight mass spectroscopy (MALDI-TOF-MS) was performed from colonies grown on TSA-SB agar plates for $18 \mathrm{~h}$ at $37^{\circ} \mathrm{C}$ using the ethanol-formic acid extraction method for better resolution and following the manufacturer's instructions (Application Note, MT-80, Microflex LT, Bruker Daltonics). Each of the strains generated similar ribosomal protein spectra, but no reliable identification was obtained using the manufacturer's database. Following manual inclusion of spectra of strain MI $10-1553^{\mathrm{T}}$ to the database, all the novel bear strains were re-analysed and matched to $S$. ursi with score above 2.2, whereas the next closest species was $S$. delphini with scores underneath 1.8 (Fig. S4). It was determined that the bear strains had specific ribosomal protein spectra which were not related to any of those of the Staphylococcus species already represented in the manufacturer's database at the time of testing.

Phenotypic characterization of the novel bear strains and reference strains S. intermedius (DSM 20373 ${ }^{\mathrm{T}}$ ), Staphylococcus cornubiensis DSM $105366^{\mathrm{T}}$, S. delphini (DSM 20771 ${ }^{\mathrm{T}}$ ) and S. pseudintermedius (CCUG $49543^{\mathrm{T}}$ ) was initially tested using both Vitek 2 GP card (bioMérieux) and API ID 32 Staph V3.0 (bioMérieux) system following the manufacturer's recommendations. Results obtained with Vitek 2 system (bioMérieux) were confirmed for overlapping tests with the API ID 32 STAPH system (bioMérieux) (Table 3). None of the additional tests present in the API ID 32 STAPH kit distinguished S. ursi from the other SIG strains. S. ursi sp. nov. can be differentiated from S. intermedius, S. pseudintermedius, S. delphini and S. cornubiensis by absence of acid production from sucrose; however, many strains of $S$. delphini showed weak reactions with sucrose and were considered as negative by Sasaki et al. [38]. The bear strains were differentiated from S. delphini (DSM $20771^{\mathrm{T}}$ ) by acid production from trehalose; however, $94 \%$ of 17 genotypically confirmed field strains of S. delphini Group A [38] also produced acid from trehalose. The S. ursi sp. nov. strains differed from S. intermedius, $S$. pseudintermedius and S. cornubiensis by acid production from methyl $\beta$-D-glucopyranoside. Absence of acetoin production was confirmed by the Voges-Proskauer test as described by Barritt [39]. Catalase activity was determined by direct application of cells from a colony to a drop of 3\% $\mathrm{H}_{2} \mathrm{O}_{2}$ on a glass slide. DNAase activity was tested on DNAase Test Agar (BBL, Becton Dickinson). Thermonuclease activity was determined by spotting $20 \mathrm{ml}$ filtered overnight culture supernatant on DNase test agar (BBL, Becton Dickinson) subsequently incubated for $2 \mathrm{~h}$ at $60^{\circ} \mathrm{C}$ and flooded with $1 \mathrm{M} \mathrm{HCl}$. Using this method, all bear strains tested negative for thermonuclease; the type strains of S. intermedius, S. pseudintermedius and S. delphini were positive. Coagulase was determined using both a rabbit plasma tube (BBL, Becton Dickinson) and slide tests (Sigma-Aldrich). Cytochrome oxidase was tested using Microdase discs (Remel). Growth assays with different salt concentrations $(6.5,9.0$ and $12.0 \%$, $\mathrm{w} / \mathrm{v} \mathrm{NaCl}$ ) and at 18,35 and $43^{\circ} \mathrm{C}$ were performed in BHI broth. Anaerobic growth was tested in thioglycolate and on blood agar plates incubated at $35^{\circ} \mathrm{C}$ in an atmosphere of $5 \%$ hydrogen, $10 \% \mathrm{CO}_{2}$ and $85 \%$ nitrogen. The Christie-AtkinsMunch-Petersen (CAMP) reaction was determined with Streptococcus agalactiae strain ATCC 12386 on Columbia Agar with 5\% sheep blood as previously described [40]. Lysostaphin susceptibility was determined by examining zones of growth inhibition surrounding discs saturated with $25 \mu \mathrm{g}$ of lysostaphin after incubation on Mueller-Hinton agar (BBL, Becton Dickinson) overnight at $37^{\circ} \mathrm{C}$.

In addition to their similarities to $S$. aureus and members of the SIG, colony phenotypes of the bear strains on TSA-SB (large, smooth, off-white with alpha hemolysis) also resembled those described for S. schleiferi [41]. In this study the novel bear strains were phylogenetically most closely related to members of the SIG and S. schleiferi occupied the next 
Table 3. Biochemical characteristics of the novel strains (Staphylococcus ursi sp. nov.) and the reference strains of the Staphylococcus intermedius group (SIG)

Strains: 1, MI 10-1549; 2, MI 10-1553T; 3, MI 10-1558; 4, MI 10-1605; 5, MI 10-1708; 6, MI 10-1710; 7, Staphylococcus intermedius DSM 20373'; 8,

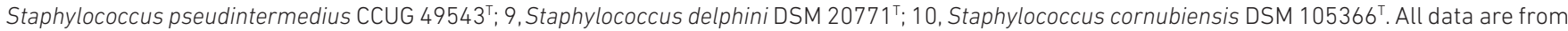
this study. +, Positive; -, negative; (+), weakly positive; (-), weakly negative.

\begin{tabular}{|c|c|c|c|c|c|c|c|c|c|c|}
\hline Characteristics & \multicolumn{6}{|c|}{ Staphylococcus ursi sp. nov. (1 to 6) } & \multicolumn{4}{|c|}{ SIG (7 to 10$)$} \\
\hline Alanine arylamidase & - & - & - & - & - & - & + & + & + & - \\
\hline Leucin arylamidase & - & $(+)$ & - & - & - & - & - & + & + & + \\
\hline L-Pyrrolidonyl-arylamidase & + & + & + & - & + & $(+)$ & + & + & + & + \\
\hline Methyl $\beta$-D-glucopyranoside & - & - & - & - & - & - & + & + & - & + \\
\hline$N$-Acetyl-D-glucosamine & + & + & - & + & + & + & - & + & + & + \\
\hline Urease & + & + & + & + & - & + & + & + & + & - \\
\hline$\alpha$-Glucosidase & - & $(-)$ & - & - & - & - & + & + & - & + \\
\hline D-Ribose & + & + & - & + & + & + & + & + & + & + \\
\hline D-Galactose & + & + & + & + & + & + & - & + & - & - \\
\hline Maltose & + & + & - & - & + & + & + & + & + & - \\
\hline D-Mannitol & + & - & + & + & $(-)$ & + & + & - & - & + \\
\hline D-Mannose & - & + & - & $(-)$ & - & + & + & + & + & + \\
\hline Sucrose & - & - & - & - & - & - & + & + & + & + \\
\hline Trehalose & + & + & + & + & + & + & + & + & - & + \\
\hline
\end{tabular}

closest clade (Figs. 1 and 2). The novel bear strains can be differentiated from S. schleiferi by the absence of acetoin production.

Based on the combined phenotypic and genotypic characteristics of the bear strains, these strains, represented by strain MI 10-1553 $3^{\mathrm{T}}$, meet criteria for being assigned to a new Staphylococcus species, for which we propose the name Staphylococcus ursi sp. nov.

\section{DESCRIPTION OF STAPHYLOCOCCUS URSI SP. NOV.}

Staphylococcus ursi (ur'si. L. gen. n. ursi of a bear).

Cells are non-motile, Gram-positive cocci $(0.5-1.5 \mu \mathrm{m})$. Well-isolated colonies are up to $2 \mathrm{~mm}$ in diameter after $24 \mathrm{~h}$ incubation at $35^{\circ} \mathrm{C}$ and exceed $5 \mathrm{~mm}$ in diameter after 5 days of growth. Colonies appear convex, smooth, off-white, lack carotenoid pigment and display $\alpha$ haemolysis on sheep blood agar. Strains have a positive CAMP reaction with Streptococcus agalactiae, indicating production of $\delta$-toxin, except strain MI 10 1558. Grows aerobically and anaerobically. Grows in 6.5, 9 and $12 \% \mathrm{NaCl}(\mathrm{w} / \mathrm{v})$ and at 43 and $18^{\circ} \mathrm{C}$. Catalase-positive, oxidase-negative and coagulase-negative. Produces thermostable nuclease with zones of hydrolysis up to $5 \mathrm{~mm}$. Positive for: arginine dihydrolase 1 (arginine dihydrolase 1 and arginine dihydrolase 2 are separate proprietary tests, each formulated to provide differentiation to the species claimed on the manufacturer's identification card), $\beta$-galactosidase, alkaline phosphatase, optochin resistance, $\mathrm{O} / 129$ resistance and acid production from glucose, fructose, lactose, trehalose and D-galactose. Negative for: arginine dihydrolase 2, ornithine decarboxylase, aesculin hydrolysis, acetoin production, arginine arylamidase, $\beta$-glucuronidase, $\alpha$-mannosidase, L-aspartate arylamidase, alanine-phenylalanine-proline arylamidase, L-proline arylamidase, tyrosine arylamidase, phosphatidylinositol-phospholipase C, cyclodextrin utilization and acid production from raffinose, cellobiose, sucrose, turanose, arabinose, xylose, sorbitol, salicin, methyl $\beta$-D-glucopyranoside, $\beta$-galactopyranoside, pullulan and D-amygdalin. Variable reactions for: pyrrolidonyl arylamidase, leucine arylamidase, $\mathrm{L}$-lactate alkalinization, $\alpha$-galactosidase, $\alpha$-glucosidase, urease and acid production from mannose, maltose, mannitol, ribose and $N$-acetyl-glucosamine. Susceptible to novobiocin and lysostaphin. Susceptible to polymyxin $B$ and variable susceptibility to bacitracin. 
The type strain is MI $10-1553^{\mathrm{T}}\left(=\mathrm{ATCC}\right.$ TSD $-55^{\mathrm{T}}=\mathrm{CCOS}$ $\left.1900^{\mathrm{T}}\right)$. This strain was isolated from the oral lip folds of a healthy black bear. The GenBank/EMBL/DDBJ accession numbers for the $16 \mathrm{~S}$ rRNA, hsp60, nuc, sodA, tagAHGBD, dnaJ and $r p o B$ gene sequences of strain MI $10-1553^{\mathrm{T}}$ are KY019172, KY056141, KY056142, KY056143, KY056144, KY496628 and KY496627, respectively. The complete genome sequence of strain MI 10-1553 ${ }^{\mathrm{T}}$ has been deposited into GenBank under accession numbers CP048279. The associated BioProject and BioSample accession numbers are PRJNA602989 and SAMN13915443, respectively. The raw reads were deposited into the SRA database with accession numbers SRR10973935 (Illumina) and SRR10973936 (ONT).

\section{Funding information}

This study was supported in part by an All Taxa Biodiversity Inventory Grant (DLIA2010-07) from Discover Life in America. Characterization of the novel species was partially conducted during the sabbatical leave of V.P. to the Department of Biomedical and Diagnostic Sciences, College of Veterinary Medicine, University of Tennessee, Knoxville, TN in 2015.

\section{Acknowledgements}

We thank Bill Stiver, Kim Delozier, John McDade (Great Smoky Mountains National Park) and John New (University of Tennessee) for assistance with sample collection and type strain depositions. For technical assistance we thank the following: Randall Kania, Mary Jean Bryant, Rebekah Jones, Brian Johnson, Matt Riley, Ellen Fleetwood, Rupal Brahmbhatt, Samar Solyman (University of Tennessee); Gottfried Dasen (Culture Collection of Switzerland CCOS); Alexandra Collaud, Alexandra Rossano, Christian Strauss, Michael Brilhante (University of Bern).

\section{Conflicts of interest}

The authors declare that there are no conflicts of interest.

\section{Ethical statement}

All animal handling and sample collection was performed by trained and certified wildlife biologists of the United States Department of the Interior, National Park Service, Great Smoky Mountains National Park in accordance with Scientific Research and Collecting permit number GRSM-2010-SCl-0028 and The University of Tennessee Institutional Animal Care and Use Committee registration number $1927-0610$

\section{References}

1. Hájek V. Staphylococcus intermedius, a new species isolated from animals. Int J Syst Bacteriol 1976;26:401-408.

2. Varaldo PE, Kilpper-Balz R, Biavasco F, Satta G, Schleifer KH. Staphylococcus delphini sp nov., a coagulase-positive species isolated from dolphins. Int J Syst Bacteriol 1988:38:436-439.

3. Devriese LA, Vancanneyt M, Baele M, Vaneechoutte M, De Graef E et al.Staphylococcus pseudintermedius sp. nov., a coagulase-positive species from animals. Int J Syst Evol Microbiol 2005;55:1569-1573.

4. Murray AK, Lee J, Bendall R, Zhang L, Sunde M et al. Staphylococcus cornubiensis sp. nov., a member of the Staphylococcus intermedius Group (SIG). Int J Syst Evol Microbiol 2018;68:3404-3408.

5. Devriese LA, Hermans K, Baele M, Haesebrouck F. Staphylococcus pseudintermedius versus Staphylococcus intermedius. Vet Microbiol 2009:133:206-207.

6. Börjesson S, Gómez-Sanz E, Ekström K, Torres C, Grönlund U. Staphylococcus pseudintermedius can be misdiagnosed as Staphylococcus aureus in humans with dog bite wounds. Eur J Clin Microbiol Infect Dis 2015;34:839-844.

7. Viau R, Hujer AM, Hujer KM, Bonomo RA, Jump RLP. Are Staphylococcus intermedius infections in humans cases of mistaken identity? A case series and literature review. Open Forum Infect Dis 2015;2:ofv110.
8. Lee J, Murray A, Bendall R, Gaze W, Zhang L et al. Improved detection of Staphylococcus intermedius group in a routine diagnostic laboratory. J Clin Microbiol 2015;53:961-963.

9. Wu MT, Burnham C-AD, Westblade LF, Dien Bard J, Lawhon SD et al. Evaluation of oxacillin and cefoxitin disk and MIC breakpoints for prediction of methicillin resistance in human and veterinary isolates of Staphylococcus intermedius group. J Clin Microbiol 2016:54:535-542.

10. Jones RD, Kania SA, Rohrbach BW, Frank LA, Bemis DA. Prevalence of oxacillin- and multidrug-resistant staphylococci in clinical samples from dogs: 1772 samples (2001-2005). J Am Vet Med Assoc 2007;230:221-227

11. Bemis DA, Greenacre CB, Bryant MJ, Jones RD, Kania SA. Isolation of a Variant Porphyromonas sp. from polymicrobial infections in central bearded dragons (Pogona vitticeps). J VET Diagn Invest 2011:23:99-104.

12. Altschul SF, Madden TL, Schäffer AA, Zhang J, Zhang Z et al. Gapped blast and PSI-BLAST: a new generation of protein database search programs. Nucleic Acids Res 1997;25:3389-3402.

13. Baron F, Cochet M-F, Pellerin J-louis, Ben Zakour N, Lebon A et al. Development of a PCR test to differentiate between Staphylococcus aureus and Staphylococcus intermedius. J Food Prot 2004;67:2302-2305.

14. Sasaki T, Tsubakishita S, Tanaka Y, Sakusabe A, Ohtsuka M et al. Multiplex-PCR method for species identification of coagulasepositive staphylococci. J Clin Microbiol 2010;48:765-769.

15. Lamers RP, Muthukrishnan G, Castoe TA, Tafur S, Cole AM et al. Phylogenetic relationships among Staphylococcus species and refinement of cluster groups based on multilocus data. BMC Evol Biol 2012;12:171.

16. Schnellmann C, Gerber V, Rossano A, Jaquier V, Panchaud Y et al. Presence of new mecA and $m p h(C)$ variants conferring antibiotic resistance in Staphylococcus spp. isolated from the skin of horses before and after clinic admission. J Clin Microbiol 2006:44:4444-4454.

17. Huang X, Miller W. A time-efficient, linear-space local similarity algorithm. Adv Appl Math 1991;12:337-357.

18. Shah MM, lihara H, Noda M, Song SX, Nhung PH et al. dnaJ gene sequence-based assay for species identification and phylogenetic grouping in the genus Staphylococcus. Int J Syst Evol Microbiol 2007:57:25-30.

19. Kwok AYC, Chow AW. Phylogenetic study of Staphylococcus and Macrococcus species based on partial hsp60 gene sequences. Int J Syst Evol Microbiol 2003:53:87-92.

20. Drancourt M, Raoult D. rpoB gene sequence-based identification of Staphylococcus species. J Clin Microbiol 2002;40:1333-1338.

21. Poyart C, Quesne G, Boumaila C, Trieu-Cuot P. Rapid and accurate species-level identification of coagulase-negative staphylococci by using the sodA gene as a target. J Clin Microbiol 2001;39:4296-4301.

22. Meier-Kolthoff JP, Göker M. TYGS is an automated highthroughput platform for state-of-the-art genome-based taxonomy. Nat Commun 2019:10:2182.

23. Meier-Kolthoff JP, Auch AF, Klenk H-P, Göker M. Genome sequence-based species delimitation with confidence intervals and improved distance functions. BMC Bioinformatics 2013;14:60.

24. Yoon S-H, Ha S-M, Lim J, Kwon S, Chun J. A large-scale evaluation of algorithms to calculate average nucleotide identity. Antonie van Leeuwenhoek 2017:110:1281-1286.

25. Lefort V, Desper R, Gascuel O. FastME 2.0: a comprehensive, accurate, and fast distance-based phylogeny inference program. Mol Biol Evol 2015;32:2798-2800.

26. Letunic I, Bork P. Interactive tree of life (iTOL) V4: recent updates and new developments. Nucleic Acids Res 2019;47:W256-W259.

27. Wayne LG, Brenner DJ, Cowell RR, Grimont PAD, Kandler 0 et al. International Committee on systematic bacteriology. Report of the $A D$ hoc Committee on reconciliation of approaches to bacterial Systematics. Int J Syst Bacteriol 1987;37:463-464. 
28. Chun J, Oren A, Ventosa A, Christensen H, Arahal DR et al. Proposed minimal standards for the use of genome data for the taxonomy of prokaryotes. Int J Syst Evol Microbiol 2018;68:461-466.

29. Götz F, Bannerman T, Schleifer KH. The genera Staphylococcus and Macrococcus. In: Dworkin M, Falkow S, Rosenberg E, Schleifer KH, Stackebrandt E (editors). The Prokaryotes, 4, 3rd edn. New York, NY: Springer; 2006. pp. pp. 5-75

30. Miller LT. A single derivatization method for bacterial fatty acid methyl esters including hydroxy acids. J Clin Microbiol 1982:16:584-586.

31. Kuykendall LD, Roy MA, O'NEILL JJ, Devine TE. Fatty acids, antibiotic resistance, and deoxyribonucleic acid homology groups of Bradyrhizobium japonicum. Int J Syst Bacteriol 1988;38:358-361.

32. Schuman P. Peptidoglycan structure. In: Rainey F, Oren A (editors). Taxonomy of Prokaryotes, Methods in Microbiology, 38. London: Academic Press; 2011. pp. pp. 101-.129.

33. Schleifer KH, Kandler O. Peptidoglycan types of bacterial cell walls and their taxonomic implications. Bacteriol Rev 1972;36:407-477.

34. Tindall BJ. A comparative study of the lipid composition of Halobacterium saccharovorum from various sources. Syst Appl Microbiol 1990a;13:128-130.
35. Tindall BJ. Lipid composition of Halobacterium lacusprofundi. FEMS Microbiol Lett 1990b;66:199-202.

36. Tindall BJ, Sikorski J, Smibert RM, Kreig NR et al. Phenotypic characterization and the principles of comparative systematics. In: Reddy CA, Beveridge TJ, Breznak JA, Marzluf G, Schmidt TM et al. (editors). Methods for General and Molecular Microbiology, 3rd ed. Washington, DC USA: ASM Press; 2007. pp. pp. 330-.393.

37. Qian Z, Yin Y, Zhang Y, Lu L, Li Y et al. Genomic characterization of ribitol teichoic acid synthesis in Staphylococcus aureus: genes, genomic organization and gene duplication. BMC Genomics 2006;7:74-85

38. Sasaki T, Kikuchi K, Tanaka Y, Takahashi N, Kamata S et al. Reclassification of phenotypically identified Staphylococcus intermedius strains. J Clin Microbiol 2007;45:2770-2778

39. Barritt MM. The intensification of the Voges-Proskauer reaction by the addition of $\alpha$-naphthol. J Pathol Bacteriol 1936:42:441-454.

40. Bemis DA, Bryant MJ, Reed PP, Brahmbhatt RA, Kania SA. Rothia nasimurium: a common cause of synergistic hemolytic reactions with Staphylococcus species in primary cultures of clinical specimens obtained from dogs. J Vet Diag Invest 2014:26:437-441.

41. Igimi S, Takahashi E, Mitsuoka T. Staphylococcus schleiferi subsp. coagulans subsp. nov., isolated from the external auditory meatus of dogs with external ear otitis. Int J Syst Bacteriol 1990;40:409-411.

\section{Five reasons to publish your next article with a Microbiology Society journal}

1. The Microbiology Society is a not-for-profit organization.

2. We offer fast and rigorous peer review - average time to first decision is 4-6 weeks.

3. Our journals have a global readership with subscriptions held in research institutions around the world.

4. $80 \%$ of our authors rate our submission process as 'excellent' or 'very good'.

5. Your article will be published on an interactive journal platform with advanced metrics.

Find out more and submit your article at microbiologyresearch.org. 